\title{
LA GESTIÓN DE LA OFERTA TURÍSTICO-CULTURAL EN LOS GRANDES HITOS PATRIMONIALES. EL CASO DE PATRIMONIO NACIONAL ${ }^{1}$
}

\author{
$M^{\mathrm{a}}$ del Carmen Mínguez García \\ Departamento de Geografía Humana. Universidad Complutense de Madrid \\ cminguez@ghis.ucm.es
}

\section{RESUMEN}

El desarrollo de los destinos culturales está directamente relacionado con la gestión de sus hitos patrimoniales, cuyos responsables realizan grandes esfuerzos para ofrecer una visita de calidad y mantener su vocación social. Todo a través de una agenda cultural, que genere ingresos extras, ofrezca empleo y fomente la diversificación de la oferta. Entre las instituciones culturales y patrimoniales sobresale Patrimonio Nacional, que en los últimos años realiza una incesante labor para acometer cambios que mitiguen la fuerte estacionalidad de las visitas y la pérdida de visitantes e ingresos, con actuaciones que afectan a numerosos destinos.

Palabras clave: stakeholder, gestión, oferta cultural, rentabilidad, Patrimonio Nacional.

\section{ABSTRACT}

Development of cultural destinations is directly related to management of their attractions. The people responsible for them make great efforts to provide a quality visit and maintain their social purpose through a cultural agenda that generates additional revenue, creates jobs in the area and encourages programme diversification. Outstanding among cultural and

Fecha de recepción: enero 2012.

Fecha de aceptación: noviembre 2012.

1 Dentro del proyecto «La capacidad de carga como instrumento de planificación y gestión de los recursos turístico-culturales». Ministerio de Ciencia e Innovación. Plan Nacional de I+D+i (2008-2011). Referencia: CSO2010-20702 GEOG. Dpto. de Geografía Humana (UCM). Años 2011-2013. Investigador principal: María García Hernández, con datos del «Estudio económico sobre las actividades culturales de Patrimonio Nacional y la comparativa con el resto de las Residencias Reales Europeas e instituciones competidoras» (2010) dirigido por $\mathrm{M}^{\mathrm{a}}$ del Carmen Mínguez García. Los resultados de esta investigación han sido parcialmente presentados en el XIII Coloquio de Geografía del Turismo, Ocio y Recreación de la AGE celebrado en Barcelona en junio de 2012. 
heritage institutions is Patrimonio Nacional, which in the last few years has worked unceasingly to make changes that mitigate the heavy seasonality of visits in the case of some assets, and the loss of visitors and revenue, with actions affecting numerous destinations.

Key words: stakeholder, management, cultural program, profitability, Patrimonio Nacional.

\section{INTRODUCCIÓN}

El turismo cultural, entendido como el movimiento de personas motivadas por la obtención de información y experiencia para satisfacer sus necesidades culturales ${ }^{2}$, es una actividad creciente y de gran importancia desde el punto de vista social y económico (Richards, 1996). Esto se debe a que esta forma de turismo se ve favorecida por las nuevas tendencias de la demanda, cada vez más interesada en la cultura y más segmentada en cuanto a conocimiento e intereses, y también por el aumento de la oferta de recursos patrimoniales y acontecimientos culturales. Así, el turismo cultural ha alcanzado un nivel de desarrollo mayor en las ciudades europeas que en otros lugares (Richards, 2001a), gracias a que cuentan con un importante patrimonio y con una potente infraestructura histórico-cultural (Montero et al, 2001).

Los museos y monumentos visitables, o musealizados, juegan un papel esencial en la creación y consolidación de los destinos culturales en los que se encuentran ubicados. Estos, en la última década, han modificado su misión y vocación adaptándose a las necesidades de la demanda y de las colecciones que albergan (Chinchilla, 2007), lo que les ha convertido en instituciones mediadoras entre ambos elementos. En consecuencia, con estos cambios, se han realizado modificaciones substanciales en la organización y dirección de los bienes patrimoniales y culturales, cada vez más abiertas a la colaboración con otras instituciones, al tiempo que más próximas a la lógica empresarial, al hacerse presente su preocupación por los problemas de financiación, mantenimiento y rentabilidad (Tobelem, 2007, Chinchilla, 2007).

Los recursos patrimoniales y culturales, es decir, los museos y monumentos, y sus entornos son la base sobre la que se construyen algunos destinos turísticos, llegando a ser el elemento diferenciador que les ha permitido, durante décadas, una posición competitiva respecto a otros lugares. Su influencia y capacidad de reclamo para la visita hace que requieran de una adaptación especial a la función turística; por lo que es necesario que los estudios sobre destinos turísticos y sobre las dinámicas territoriales causadas por esta actividad, aporten información que permita conocer las estrategias de gestión de las instituciones culturales y sus expectativas de cara al futuro.

\section{LOS HITOS PATRIMONIALES EN LOS DESTINOS CULTURALES}

Actualmente, en España se distinguen seis grandes tipos de recursos patrimoniales que muestran un importante nivel de adecuación para la visita. Estos son: 1. los bienes de uso de la Corona gestionados por «Patrimonio Nacional»; 2. los elementos que constituyen el Patrimonio Religioso, pertenecientes a la Iglesia Católica; 3. los grandes museos, tanto de propiedad pública como privada; 4. el Patrimonio Arqueológico y Paleontológico y 5. los

2 Definición establecida en el Programa ATLAS, por la Asociación para la Educación, Turismo y Ocio. 
monumentos relevantes, que corresponden a edificios aislados y los conjuntos monumentales (García y De la Calle, 2012). Pero no todos los elementos que componen el repertorio de los recursos del patrimonio español son iguales, y tan sólo una minoría son atractivos y están adecuados para la visita pública; es decir, forman lo que los expertos anglosajones llaman «attractions» (Richards, 2001b) o lo que en España se denominan «hitos patrimoniales» (García y De la Calle, 2012). Estos cumplen los siguientes requisitos: a) ser conjuntos edificados de elevado valor arquitectónico, pudiendo presentar dimensiones urbanísticas, b) ser importantes referentes turísticos dentro de los destinos en los que se ubican, convirtiéndose en las principales atracciones, por lo que su visita pública requiere de especial atención y c) presentar un modelo de gestión unitaria que aborde el bien de una forma integral.

\subsection{La gestión turístico-cultural de los hitos patrimoniales}

En todos los hitos patrimoniales la gestión de la visita y de la oferta cultural, entendida como las actividades de carácter cultural y pedagógico programadas por la institución, juegan un papel destacado y despiertan un gran interés en los gestores culturales y patrimoniales. Estos tienen por misión proteger los bienes que están a su cargo, al tiempo que presentan una vocación social como instrumentos educativos y de fruición (Alonso, 1991, Vacas, 2000). Dicha misión está en sintonía con el importante proceso de democratización de la cultura y de las políticas culturales, que se ha consolidado en las últimas décadas (Castells, 1997; Fleury, 2006); al tiempo que se adapta a las necesidades de una sociedad, caracterizada por un mayor nivel de vida y educativo, que busca lo diferente y lo auténtico, entendido esto como lo más lejano temporal, espacial y culturalmente (Santana, 2003). Se trata de una sociedad que quiere experimentar y selecciona los lugares y las actividades culturales en función de criterios vivenciales, estéticos y de modas, con un marcado carácter esnobista que fomenta el coleccionismo de lugares (Urry, 1995, Cohen, 2005). De forma que la relación de la demanda con el patrimonio y la cultura cambia, pero también lo hace la relación entre el público y las instituciones culturales, reforzándose, a través de la diversificación de la oferta, la creación de nuevos espacios expositivos (Ballé, 2003) y la implantación de nuevas formas de comunicación más interactivas y dinámicas.

Así, los gestores se enfrentan hoy en día a tres grandes retos. En primer lugar, garantizar el estado de conservación de los bienes que están a su cargo, que en numerosas ocasiones ven potenciada su fragilidad consecuencia de la afluencia masiva de visitantes. En segundo lugar, asegurar una visita de calidad que se adapte a las necesidades de una demanda creciente y especializada, al tiempo que cada vez más atraída por el patrimonio y la cultura, entendidas como experiencias. En tercero, y último lugar, sufragar los elevados costes que implica la conservación y la consolidación de una oferta cultural atractiva y variada que, si bien no aporte beneficios económicos, ayude a conseguir la autofinanciación de los bienes.

A nivel internacional los grandes hitos culturales, como el Metropolitan, el MoMa, el Louvre, la Tate Gallery o el Palacio de Versalles entre otros, asumieron estos tres desafíos en el marco de una gran reflexión sobre su misión, a finales del siglo pasado o durante los primeros años del presente. En ese momento muchos de ellos iniciaron un proceso de transformación sin precedentes, que implicaba su expansión, renovación, diversificación y deslocalización (Gomboult, 2003). Esta no sólo conllevaba alteraciones e intervenciones físicas, como el aumento de la superficie visitable, mejoras en la accesibilidad, cambios en el discurso museográfico y 
la dotación de equipamientos, sino también importantes transformaciones institucionales que afectaban tanto a las actividades propuestas como a la capacitación del personal empleado, la organización interna o su inserción en la sociedad (Kavanagh, 1994; Ballé, 2003). De forma que los museos y monumentos han accedido al nivel de institución cultural gracias a que han tenido la capacidad de movilizar todos los recursos compatibles para conseguir ese fin, en un proceso en el que la cultura y la economía se aproximan, máxime en países sujetos a los mercados, en los que se considera la cultura un sector más de la misma (Chatelain, 1998).

Todas estas modificaciones hacen que la gestión se racionalice y la organización se haga cada vez más compleja, requiriéndose la dotación de un estatus jurídico y administrativo que les permita una autonomía de gestión (Ballé, 1996; Gomboult, 2003), esencialmente gracias a la constitución de fundaciones y asociaciones. Así, las principales instituciones disponen de formas organizativas más flexibles y comienzan a gestionarse como empresas culturales (Selbach, 2000). En ellas la gestión presupuestaria adquiere una gran relevancia, más aún en épocas de crisis como la actual, de manera que la calidad de la visita y de la oferta cultural es medida en términos de afluencia y, por lo tanto, de ingresos económicos.

La autonomía de gestión se observa con cierta claridad en las principales instituciones culturales españolas como los museos del Prado, Thyssen, Reina Sofía o la Alhambra, a pesar de que económicamente están reguladas por Ley General Presupuestaria ${ }^{3}$ y, por lo tanto, dependen de manera total o parcial de las subvenciones reconocidas en los Presupuestos Generales del Estado. Un hecho que sin duda conlleva una serie de ventajas, como es la comodidad de contar con unos ingresos garantizados, pero también con notables inconvenientes. Entre ellos, los más importantes son la fuerte politización de las actuaciones, ciertas limitaciones presupuestarias, la falta de motivación para innovar y conseguir medios complementarios para la subsistencia y, en el caso de aquellas instituciones que facturan grandes cantidades, la imposibilidad de disponer de las rentas que generan (Lord y Lord, 1998).

Por estas razones las instituciones culturales españolas de mayor renombre han adquirido flexibilidad e independencia, siendo cada vez más frecuente que se establezcan como instituciones híbridas (Albi, 2003). Así, obtienen una mayor agilidad en la gestión económica (contrataciones, pagos, etc.) al tiempo que se procura que consigan medios de subsistencia complementarios -rara vez sustitutivos- a los oficiales. Esto último, va a favorecer un modelo de gestión por objetivos que conlleva el planteamiento de fines a medio y largo plazo; que se desarrollen estrategias de marketing; se diversifique su oferta y establezcan alianzas y colaboraciones con otros agentes, para cuyo cumplimiento se requiere una independencia política que también queda garantizada mediante la autonomía de gestión (Lord y Lord, 1998, Albi, 2003). Precisamente, la inclusión de los museos en una lógica económica, en ocasiones sin un debate previo sobre cuáles son los límites éticos, funcionales y sociales aceptables, ha motivado que sus necesidades financieras aumenten con objeto de la autofinanciación. Algo idílico y difícilmente alcanzable por las instituciones culturales europeas, pero que ha causado la búsqueda de estrategias para aumentar los recursos, entendiendo los museos como negocios, pese a que por definición son instituciones sin ánimo de lucro.

3 Ley General Presupuestaria, aprobada por Real Decreto Legislativo 1091/1988, de 23 de septiembre y la Ley 6/1997, de 14 de abril, de Organización y Funcionamiento de la Administración General del Estado. 


\subsection{El papel de las instituciones culturales y patrimoniales en los destinos de visita cultural}

Se pueden definir los destinos turísticos como aquellos espacios en los que se desarrollan las actividades de producción y consumo turístico, así como donde se muestran sus impactos económicos, sociales o territoriales (Barrado, 2004). Su interés y especificidad formal y funcional (Vera et al, 1997) los ha convertido en un importante foco de estudio que, hasta la fecha, ha sido abordado con diferentes ópticas según los distintos autores. Partiendo de la idea de que el turismo es una actividad compleja y transversal y en la que interviene numerosos actores o agentes locales, cada vez son más frecuentes las investigaciones basadas en la Teoría General de Sistemas, que reconocen los destinos turísticos como sistemas en los que intervienen una serie de elementos relacionados entre sí, tales como agentes, políticas, recursos o visitantes (Merinero y Pulido, 2009).

Actualmente, se considera que el potencial de desarrollo de los destinos, y por lo tanto su éxito, está vinculada directamente con la capacidad de gestión de las partes interesadas, así como con las relaciones que establecen entre sí. De esta manera, los destinos se configuran y articulan turísticamente como el resultado de una suma de acciones realizadas por los diferentes actores implicados, también llamado stakeholders ${ }^{4}$; de forma que se requiere de la colaboración entre ellos para crear destinos y productos turísticos (Merinero y Zamora, 2009).

Entre los destinos culturales destacan las ciudades históricas al ser, por excelencia, espacios de la cultura que albergan un elevado número de hitos patrimoniales y de instituciones culturales. Además, muchas de ellas han sido reconocidas como Ciudades Patrimonio Mundial o Ciudades y Capitales Europeas de la Cultura. Los estudios realizados sobre estos espacios muestran, precisamente, la dificultad existente para aunar los esfuerzos entre agentes culturales, turísticos, sociales y urbanísticos, con el fin de consolidar una oferta turística coherente y de calidad (De la Calle y García, 1998). Esta falta de comunicación y entendimiento conlleva una serie de problemas que impide que los destinos de motivación cultural rentabilicen los recursos turísticos como elementos esenciales en su desarrollo económico local; y es que el turismo adquiere un papel esencial en la gestión integral de las ciudades, al permitir visualizar la dimensión económica del patrimonio (Troitiño y Troitiño, 2009). De ahí que el modelo de gestión desarrollado por las instituciones culturales y patrimoniales no sea de interés exclusivamente interno, sino que adquiera gran importancia para la localidad en la que se encuentra, ya que cualquier modificación en la agenda cultural, los horarios o las tarifas implicará cambios en la forma de visita y por lo tanto repercutirán en el destino. Ciertamente, la incomunicación entre los agentes turísticos y cultuales, debido a sus diferentes visiones (Velasco, 2009), afecta de forma directa a la localidad, siendo numerosos e importantes los problemas que derivan de esta falta de relación y entendimiento:

- La focalización espacial de la visita es debida a la gran dificultad que supone una correcta interpretación y puesta en valor de determinados tipos de patrimonio, así

4 El término stakeholders fue acuñado en el ámbito empresarial, en la década de los 80 y, según su precursor Richard. E. Freeman, hace referencia a cualquier grupo o individuo que pueda afectar o ser afectado por el logro de los objetivos de una empresa. 
como a la falta de acondicionamiento de grandes contenedores culturales, que favorezca la diversificación del producto patrimonial clásico a través de una oferta cultural innovadora (Troitiño et al, 1998). Ambos factores conllevan que los visitantes centren su atención exclusivamente en determinados hitos, infrautilizando el resto del patrimonio y produciéndose un uso turístico selectivo del destino y de sus recursos, que determina el espacio denominado «Ciudad histórico-turística» (De la Calle, 2002). En algunos casos esta concentración espacial, potenciada por la estacionalidad, ocasiona importantes problemas de saturación y congestión turística que se pueden resolver con una política que favorezca la diversificación de la oferta, que implique a otras áreas de la ciudad y que no sea tendente a la concentración de las actividades en la zona monumental (Mínguez, 2007).

- La estacionalidad de las visitas es un problema asociado esencialmente a la demanda que, aunque actualmente dispone de una mayor flexibilidad en cuanto a fechas para realizar sus viajes, todavía sigue desplazándose esencialmente durante los periodos vacacionales clásicos (Semana Santa, verano y puentes). En realidad la estacionalidad también está muy vinculada a la oferta, de manera que el diseño de una agenda de actividades culturales equilibrada en el tiempo resulta esencial a la hora de distribuir de forma homogénea los flujos de visitantes. Esta situación incide en los niveles de saturación (OMT, 2004), generando problemas de conservación, pero también repercute en las infraestructuras, servicios y mano de obra, así como en la inflación de los precios (García, 2004).

- La corta duración de la estancia y, más concretamente el excursionismo, es un hecho que está unido al elevado nivel de repetición de las visitas. Se produce como consecuencia de la falta de una oferta variada e interesante por parte de las instituciones culturales, que invite a destinar más tiempo a la visita de ese lugar. También puede ser resultado de la falta de difusión de dicha oferta y del consiguiente desconocimiento de la misma antes de organizar el viaje, por lo que se deben fortalecer los canales de información en origen (Internet, publicidad, medios de comunicación, etc.) y no en destino (Oficinas de Turismo, cartelería, etc.). Esta situación perjudica directamente a la economía local, al generar un nivel de gasto inferior al ocasionado por la actividad turística de larga duración.

- Una adaptación insuficiente a las nuevas demandas, cada vez más exigentes, hace necesario diversificar la oferta, canalizar la atención de los visitantes hacia nuevos recursos, más creativos e innovadores, y acondicionar determinados bienes que son atractivos en sí mismos, creando productos novedosos (Ávila y Barrado, 2005). Para ello es preciso establecer estrategias de recuperación y adecuación para la visita, en las que los agentes culturales resultan esenciales.

- La ausencia de comunicación entre los agentes patrimoniales y turísticos está asociada a la imagen que se crea de los destinos. Ésta, muy frecuentemente, se ha construido exclusivamente sobre los museos y monumentos, de manera que su organización y las intervenciones que en ellos se realicen serán decisivas, al tiempo que se retroalimentan los problemas anteriormente mencionados. Una buena gestión de los hitos patrimoniales favorece un mejor desarrollo de las actuaciones realizadas por el destino, así como de su imagen, revirtiendo todo en una mejor experiencia de la visita. 
En este sentido hay que destacar que hasta hace escasamente un par de décadas los especialistas de la cultura no han tenido conocimiento de la importancia del mercado turístico ni, sobre todo, de las repercusiones que sus actuaciones tienen en los municipios en los que se encuentran. Pero cada vez más, asumen que una fluida relación entre agentes favorece a los destinos y también a ellos mismos. Y es que los propios agentes patrimoniales y culturales también necesitan fortalecer el contacto con sus entornos, como consecuencia de la necesidad de ingresos que presentan y del consiguiente acercamiento al público. Hasta el momento hay que señalar que la relación con los agentes municipales es cuanto menos simbólica, ya que algunos responsables de la administración local comienzan a formar parte de los patronatos de las fundaciones encargadas de la gestión patrimonial, lo que pone de manifiesto la importancia y el abolengo de estos entes. El problema radica en que habitualmente la relación se limita a esa esfera, sin llegar a forjar un vínculo práctico ni de trabajo conjunto. Prueba de ello es que pese a que los museos desempeñan un papel cada vez más importante en el desarrollo del territorio en el que se encuentran, en las estrategias de inclusión social (Ballé, 2003) y en la consolidación de los destinos (Troitiño y Troitiño, 2008), todavía siguen sin desarrollarse sólidas acciones conjuntas entre las instituciones culturales y los ayuntamientos.

\section{OBJETIVOS Y METODOLOGÍA DEL TRABAJO}

A nivel nacional, destacan los bienes de propiedad pública vinculados a la Corona, que son gestionados por Patrimonio Nacional. Estos, debido a su monumentalidad y simbología, se han consolidado como recursos turísticos y han generado importantes destinos de visita cultural desde finales del siglo XIX. En los últimos años, Patrimonio Nacional ha demostrado haber asumido su papel como una de las principales instituciones culturales españolas buscando estrategias que mejoren y modernicen sus actuaciones. Se podría decir que pretende dar un paso más en la gestión de sus bienes con el fin de compatibilizar los aspectos anteriormente mencionados -conservación y visita pública-con la rentabilidad económica a través de eventos culturales.

$\mathrm{Su}$ función como agente patrimonial es fundamental en la configuración de destinos como Madrid, Aranjuez, La Granja de San Ildefonso o San Lorenzo de El Escorial, entre otros, lo que lo convierte en un importante objeto de estudio y en el tema central de este artículo. Resulta esencial realizar un análisis de sus actuaciones en materia turística y de programación cultural en cada uno de esos lugares, así como estudiar las repercusiones que en ellos tiene. Una labor que ha de acometerse con una visión crítica y atendiendo a la oferta actual que propone esta institución, al modelo de gestión de la visita pública y valorando -en términos de ingresos- el coste de oportunidad que deja de percibir.

Para ello se tienen en cuenta los siguientes aspectos: 1 . que los recursos culturales de los que dispone se pueden rentabilizar económicamente, más allá de la oferta museística, a través de nuevas actividades que mediante una figura de gestión permitan la autofinanciación, 2. que el establecimiento de una oferta cultural complementaria de calidad refuerza los destinos patrimoniales y genera un mayor número de visitantes y 3. que la actividad va a favorecer el desarrollo económico de los municipios implicados a través de los beneficios que genera el turismo cultural. Estos tres aspectos fueron tenidos en cuenta para la elaboración 
del proyecto de investigación titulado «Estudio económico sobre las actividades culturales de Patrimonio Nacional y la comparativa con el resto de las Residencias Reales Europeas e instituciones competidoras», encargado en 2010 por dicha institución a la empresa Lear Estrategia Cultural y en el que participó directa y activamente la autora del artículo.

Desde el punto de vista metodológico el citado estudio contó con dos apartados independientes: el primero consistió en el análisis de la oferta cultural que Patrimonio Nacional propuso entre 2007 y 2009, periodo incrementado en dos años para este artículo, al no estar publicados oficialmente los datos del 2012 en el momento de su aceptación. Con ello se establecía un punto de partida al tiempo que se conocía el modelo de gestión llevado a cabo por la institución. En este proceso ha sido necesario analizar los programas culturales, los costes de las actividades, la afluencia a las mismas, los convenios, etc. En definitiva, información interna a la que se ha tenido acceso directamente, a través de las conversaciones con los responsables de cada área, o de los resúmenes recogidos en las Memorias Anuales.

El segundo apartado del estudio consistió en la realización de un análisis comparativo y sistemático con otras instituciones culturales, nacionales e internacionales, consideradas de referencia, a través de la técnica del benchmarking. Entre las primeras se encontraban los conjuntos patrimoniales y museos de titularidad y gestión pública, como La Alhambra o los once Museos Estatales ubicados en la ciudad de Madrid. Según el Ministerio de Cultura ${ }^{5}$ estos son: el Museo Arqueológico Nacional, el Museo Cerralbo, el Museo de América, el Museo del Traje CIPE, el Museo Nacional de Antropología, el Museo Nacional de Artes Decorativas, el Museo Nacional del Romanticismo, el Museo Sorolla, Museo Lázaro Galdiano, Museo Nacional Centro de Arte Reina Sofía y el Museo Nacional del Prado. A ellos se añadió el Museo Thyssen Bornemisza, que si bien no es un museo estatal posee titularidad pública aunque con autonomía de gestión. Este, junto con el Prado, es considerado competencia directa de Patrimonio Nacional, de ahí que se les dedique especial atención. Paralelamente, se descartó un gran número de bienes con titularidad autonómica o local por considerar que se encuentran fuera del ámbito geográfico del análisis.

Entre las instituciones internacionales se concedió especial protagonismo a las acciones realizadas por los miembros de la Asociación de Residencias Reales Europeas ${ }^{6}$ (ARRE), a la que pertenece Patrimonio Nacional desde la fundación, en 1995, de su antecesora, la Red Europea de Residencias Reales. De sus dieciséis miembros ${ }^{7}$ se eligieron seis por contar con

5 http://www.mcu.es/museos/index.html (consulta 13 de abril de 2012)

6 Heredera de la Red Europea de Residencias Reales constituida, en 1995, dentro del programa europeo Raphael, la Asociación se consolida en 2001 como un espacio de intercambio de experiencias y capacitación para los gestores de las residencias reales ubicadas en Europa. Para ello periódicamente desarrolla proyectos, que cuentan con la financiación de la Comisión Europea, y que persiguen construir y difundir una historia europea compartida; dar a conocer la importancia del patrimonio y favorecer el desarrollo de las buenas prácticas.

7 Forman parte de la ARRE: Palacios y jardines Prusianos de Berlín y Brandeburgo (Alemania), Palacio de Schönbrunn (Austria), Antiguo Palacio Real de Bruselas (Bélgica), Castillo de Rosenborg (Dinamarca), Patrimonio Nacional (España), el Castillo Nacional de Chambord y el Palacio de Versalles (ambos en Francia), Palacio Real de Gödölló (Hungría), Palacio Real de Caserta y Residencias Reales de Turín y de Piamonte (Italia), Palacio de Het Loo (Países Bajos), Museo del Palacio de Wilanów (Polonia), Palacio Nacional de Mafra (Portugal), Palacio de Hampton Court (Reino Unido), Museo de Peterhof (Rusia), Palacio Real de Estocolmo (Suecia). 
una importante y variada oferta cultural: Palacios de Potsdam (Alemania), Turín (Italia), Hampton Court (Reino Unido), Schönbrunn (Austria), Versalles y Chambord (Francia).

Con la información recabada en todos estos lugares se presentaron diferentes escenarios económicos considerando la oferta cultural, el público y las políticas de precios. Ahora, dos años más tarde, en este artículo se muestran algunos de los resultados del citado estudio con el objetivo último de analizar las repercusiones que la gestión turístico-cultural de Patrimonio Nacional tiene en los destinos turísticos en los que tiene presencia.

\section{PATRIMONIO NACIONAL: EL MODELO DE GESTIÓN DE UNA INSTITUCIÓN POLIFACÉTICA}

Patrimonio Nacional nace el 7 de marzo de 1940, como unidad jurídica indivisible, con la finalidad de gestionar y administrar los bienes (muebles e inmuebles) de vinculación con la Corona, tanto de carácter civil como religioso. Se convierte así en la heredera de otras instituciones anteriormente reconocidas bajo el nombre de Patrimonio Real (hasta 1865), Patrimonio de la Corona (1865-1932) y Patrimonio de la República (1932-1940), poniendo fin a la dispersión funcional existente hasta ese momento (Díez, 1989).

Ya en democracia, y bajo el mismo nombre adquirido en la dictadura, Patrimonio Nacional es reconocido por la Constitución Española como una opción político-constitucional, al tiempo que establece su configuración y marco legal propio. La Ley 23/1982, de 16 de junio, Reguladora del Patrimonio Nacional reconoce y define su Consejo de Administración que «se configura como una Entidad de Derecho público, con personalidad jurídica y capacidad de obrar, orgánicamente dependiente de la Presidencia del Gobierno y excluida de la aplicación de la Ley de Entidades Estatales Autónomas» (art. 1LPN). Esta misma ley establece que tiene como fines la gestión y administración de una serie de bienes y derechos de patronato o gobierno y administración sobre las Fundaciones denominadas Reales Patronatos ${ }^{8}$ (art. 1, 4 y 5LPN) (fig.1), centrándonos en este texto exclusivamente en los primeros, los bienes.

Patrimonio Nacional gestiona los bienes de titularidad del Estado que se encuentran «afectados al uso y servicio del Rey y de los miembros de la Real Familia para el ejercicio de la alta representación que la Constitución y las leyes les atribuyen» (art. 2.I LPN), lo que le concede una particularidad especial y única en Europa. Además, como todos los bienes de dominio público, son inalienables, imprescriptibles e inembargables y gozan de exenciones tributarias. Igualmente, la ley recoge la posibilidad de compatibilizar la función principal de la alta representación del Estado, con otras actividades de carácter cultural, científica y docente, así como la visita pública. Aspecto este último que ha ganado importancia en los últimos años, como consecuencia del aumento de la demanda y por el interés que atañen los propios bienes. Todo ello hace que ésta sea una institución compleja y única, a la vez que presenta un gran interés para la investigación.

8 Reales Patronatos: Iglesia y Convento de la Encarnación, Iglesia y Hospital del Buen Suceso, Convento de las Descalzas Reales, Real Basílica de Atocha y Panteón de Hombres Ilustres, Iglesia y Colegio de Santa Isabel e Iglesia y Colegio de Loreto, todos ellos en Madrid. Monasterio de las Huelgas y Hospital del Rey, ambos en Burgos, Convento de Santa Clara en Tordesillas, Convento de San Pascual en Aranjuez, Copatronato del Colegio de Doncellas Nobles en Toledo y La Mareta en Lanzarote. 


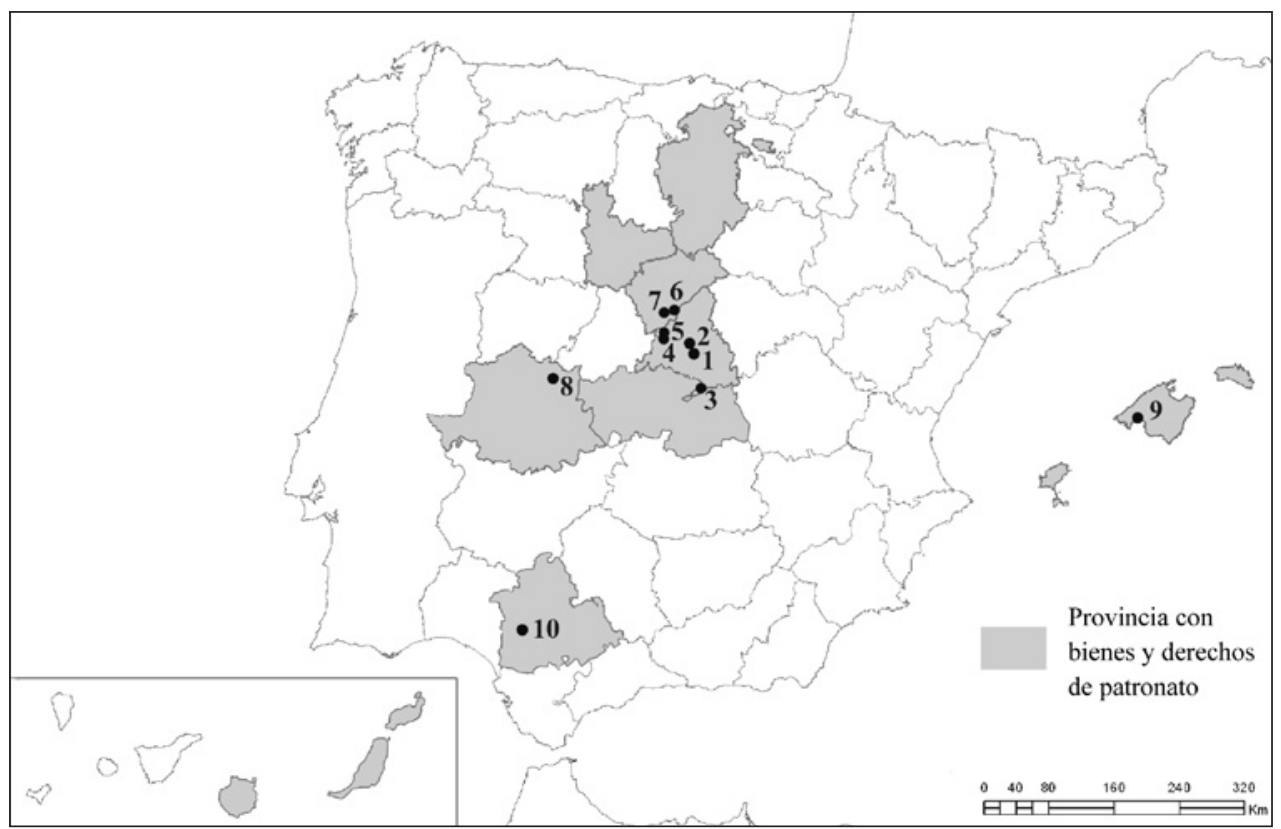

Bienes que componen Patrimonio Nacional: 1: Palacio Real de Madrid, 2: Real Sitio de El Pardo, 3: Real Sitio de Aranjuez, 4: Real Sitio de San Lorenzo de El Escorial, 5: Valle de los Caídos, 6: Real Sitio de La Granja de San Ildefonso, 7: Real Sitio de Riofrío, 8: Monasterio de San Jerónimo de Yuste, 9: Palacio de la Almudaina y 10. Reales Alcázares de Sevilla.

Fuente: Elaboración propia con datos de la Ley 23/1982, de 16 de junio, Reguladora del Patrimonio Nacional.

\subsection{La gestión de la visita pública}

Patrimonio Nacional se encarga de gestionar un valioso patrimonio, de gran significado histórico y artístico, así como de gran singularidad y riqueza, que se presenta con una enorme variedad patrimonial, arquitectónica, mobiliaria, urbanística, medioambiental y paisajística. Entre los elementos que lo componen destacan algunos de los principales hitos patrimoniales españoles, de reconocido interés a escala nacional e internacional, cuya calidad les ha hecho merecedores de las declaraciones como Bienes de Interés Cultural (Ley de Patrimonio Histórico Español) e incluso de las declaraciones de la UNESCO como Sitio Patrimonio de la Humanidad, en el caso de San Lorenzo de El Escorial (1984) y como Paisaje Cultural de la Humanidad en el del Real Sitio de Aranjuez (2001). Su reconocimiento y revalorización han influido en el auge del turismo experimentado por los destinos en los que se encuentran, en especial el turismo vinculado con la visita a lugares «patrimoniales» (García y Mínguez, 2005). Esto ha motivado que los bienes de Patrimonio Nacional reciban, en su conjunto, alrededor de tres millones de visitas anuales ${ }^{9}$, distribuidas de forma desigual entre los diferentes

9 En el año 2011 la totalidad de los museos gestionados por Patrimonio Nacional registraron 2.609.615 visitas. 
elementos, lo que genera un importante problema desde el punto de vista de la gestión unitaria. Concretamente, el Palacio Real de Madrid, por su ubicación en la capital, atrae el doble de visitas que el siguiente más visitado, el Real Monasterio de San Lorenzo de El Escorial.

Figura 2

EVOLUCIÓN DE LAAFLUENCIAA LOS PRINCIPALES MONUMENTOS DE PATRIMONIO NACIONAL 1991-2011

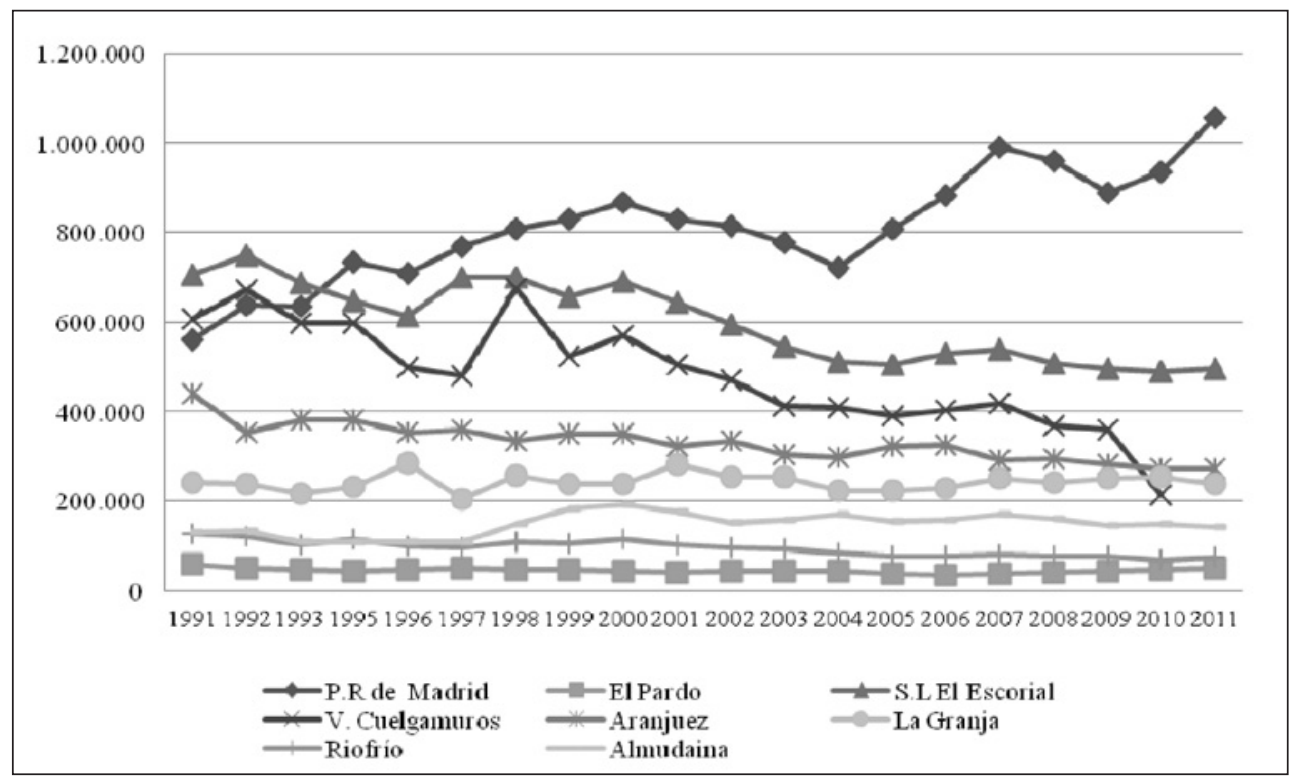

Fuente: Elaboración propia con datos de las Memorias anuales del Patrimonio Nacional.

(*) El Valle de Cuelgamuros, conocido como el Valle de los Caídos, se cerró la visita pública en febrero de 2010, de ahí el descenso de ese año y la ausencia de datos en 2011.

Tan solo el Palacio Real de Madrid y el de El Pardo muestran una tendencia creciente en el periodo 2009-2011, poniendo de manifiesto que la pérdida de visitantes y, por lo tanto de ingresos, es uno de los problemas más acusados de esta institución. Pese a esta merma, los conjuntos palaciegos y conventuales vinculados a la Corona se han convertido en atractivos turísticos de larga tradición, que centran la atención de un importante número de visitantes (fig.2). Hecho que no exime de problemas, bien al contrario, la afluencia se torna masiva en determinados lugares y momentos, ocasionando importantes problemas de conservación y en la calidad de la visita. Esto ha motivado que, en los últimos años, se vigile la capacidad de carga de las estancias musealizadas, estableciéndose un control de la afluencia basado en la experiencia propia y en las características de cada lugar. Así, en el mejor de los casos no se pueden superar las 25 personas por grupo acompañado por un guía. Esta presión no se limita a los bienes inmuebles y a sus jardines, sino que afecta también a sus entornos inmediatos y, por extensión, a los destinos de los que forman parte, donde la afluencia es mucho más difícil de controlar. En este sentido, resulta imprescindible la coordinación fluida y eficaz entre la gestión del destino y la gestión del bien. 
Otro de los problemas frecuentes en estos bienes es la fuerte estacionalidad mensual y semanal a la que se ven sometidos y que han ocasionado cambios recientes en la política de gratuidad. Tradicionalmente, el acceso gratuito para todos los europeos, estudiantes, desempleados y jubilados se realizaba durante la jornada de los miércoles, pero este estatus ha sido cambiado desde el primer semestre de 2011, a las tardes de los miércoles y de los jueves. Con esta medida se favorece el aumento de visitas en los horarios de tarde, menos frecuentados por los grupos comerciales y escolares, que se concentran en las primeras horas de la mañana. Asimismo, se asemeja más a la política llevada a cabo en el Museo del Prado o en Museo Reina Sofía, que tienen su acceso gratuito a todo el público durante las dos últimas horas todas las tardes ${ }^{10}$.

Patrimonio Nacional presenta además una casuística propia que consiste en que gestiona un patrimonio vivo y multifuncional, en el que la actividad turística es una de las muchas que se desarrollan. De manera que tanto su valorización y acondicionamiento para la visita, como la oferta de actividades pedagógicas y culturales están sujetas a su uso institucional (recepciones, almuerzos, cenas de gala, etc.) que determinan los horarios, la vigilancia y la preparación de espacios muy distintos de los establecidos en museos, que podrían llamarse más convencionales. Precisamente, ese dinamismo y la autenticidad de sus bienes -de uso en la actualidad- es un atractivo en sí mismo al tiempo que supone un gran reto para la gestión de la visita pública.

\subsection{La gestión cultural}

Desde la aprobación de la Ley de Patrimonio Nacional, esta institución ha realizado actividades culturales (exposiciones temporales, conciertos, conferencias, actividades didácticas...) de carácter gratuito, salvo excepciones que, mediante la colaboración con otras instituciones tales como la Comunidad de Madrid o Caja Madrid, requieren su cobro. Todas ellas han ido aumentando y mejorando con el paso de los años, hasta que, desde el 2006, como consecuencia a un cambio en la dirección en la Vocalía Asesora de Actividades Culturales, se modificaron las estrategias. A partir de ese momento comenzó a diseñar y ejecutar su propio ciclo de conciertos, al tiempo que mantuvo la oferta preexistente, cuyo objetivo era dar una mayor divulgación a la institución y a su patrimonio, así como mejorar la gestión en términos económicos y de innovación (Patrimonio Nacional, 2010). Durante los siguientes años se realizó un número ligeramente mayor de actividades con una nutrida afluencia, llegando a superar en 2008 y 2009 las 300.000 personas (tabla 1). Entre ellas destacan algunas nuevas como los programas educativos y la participación, durante el periodo 2007-2010, en «La noche en blanco», en colaboración con el Ayuntamiento de Madrid.

10 Acceso gratuito al Museo del Prado: las tardes de lunes a sábados 18:00 a 20:00 y los domingos de 17:00 a 19:00 y al Museo Nacional Centro de Arte Reina Sofía de Lunes a viernes de 19:00 a 21:00, los sábado de 14:30 a 21:00 y los domingos por la mañana de 10:00 a 14:30. 
Tabla 1

EVOLUCIÓN DE LAAFLUENCIA A LAS ACTIVIDADES CULTURALES DE PATRIMONIO NACIONAL EN SUS DISTINTAS SEDES (2007-2011)

\begin{tabular}{|l|r|r|r|r|r|}
\hline & \multicolumn{1}{c|}{$\mathbf{2 0 0 7}$} & \multicolumn{1}{c|}{$\mathbf{2 0 0 8}$} & \multicolumn{1}{c|}{$\mathbf{2 0 0 9}$} & \multicolumn{1}{c|}{$\mathbf{2 0 1 0}$} & $\mathbf{2 0 1 1}$ \\
\hline Exposiciones temporales & 238.304 & 292.807 & 278.912 & 175.203 & 153.366 \\
\hline Noche en Blanco & 5.000 & 20.000 & 30.000 & 15.788 & $\begin{array}{r}\text { No se } \\
\text { celebró }\end{array}$ \\
\hline Programas educativos & 1.350 & 7.200 & 8.418 & 9.726 & 11.182 \\
\hline Actividades académicas & 2.600 & 1.054 & 350 & 11.068 & 1.555 \\
\hline Actividades musicales & 30.300 & 46.250 & 34.721 & 39.200 & 30.150 \\
\hline Programas educativos & 1.350 & 7.200 & 8.418 & 9.726 & 11.182 \\
\hline $\begin{array}{l}\text { Actividades académicas y } \\
\text { científicas }\end{array}$ & Sin datos & 1.054 & Sin datos & 11.068 & 1.555 \\
\hline Veladas poéticas & 900 & Sin datos & 350 & Sin datos & Sin datos \\
\hline TOTAL & $\mathbf{2 7 7 . 9 6 3}$ & $\mathbf{3 6 7 . 7 6 1}$ & $\mathbf{3 5 0 . 8 8 3}$ & $\mathbf{2 8 5 . 0 4 5}$ & $\mathbf{1 9 9 . 2 5 3}$ \\
\hline
\end{tabular}

Fuente: Elaboración propia con datos de las Memorias anuales del Patrimonio Nacional.

A lo largo del año 2011 se organizaron más de sesenta y cinco actividades con contenido histórico-artístico. Esto supuso una inversión importante en materia de programación, montaje, seguridad, apertura en horarios extraordinarios, etc, sin aportar beneficios económicos directos. Deben exceptuarse los 60.000€ del ciclo de Música Antigua en los Reales Sitios de la Comunidad de Madrid (20€ por persona y concierto) y los aproximadamente 105.600€ que aporta la venta de cada uno los abonos del Ciclo «Los Siglos de Oro» (132€/abono). De estas cantidades, Patrimonio Nacional percibe anualmente una cantidad fija -no pública- en concepto de cesión del espacio.

Pese a que la participación siguió siendo alta, se observa una tendencia descendente respecto a la de años anteriores, en los que cada tipología de actividades registraba una afluencia mayor. Este declive se debe esencialmente a una disminución importante de la oferta y a la influencia que la crisis económica ha tenido, reduciendo el número de visitas, especialmente, tras el cambio realizado en la política de gratuidad de Patrimonio Nacional. Esta modificación implica el cobro, desde 2011, de algunas de las exposiciones temporales, entre 4 y 10€/persona, lo que ha conllevado una caída que podría haber sido mayor de no ser por la exposición «Polonia. Tesoros y colecciones artísticas», para la que se trasladaron al Palacio Real de Madrid 196 obras procedentes del Museo Nacional de Cracovia, entre las que destacaba, como principal reclamo, la Dama del Armiño de Leonardo da Vinci. Pese a contar con esta obra y a coincidir la exhibición con la Jornada Mundial de la Juventud, que conllevó el desplazamiento de cientos de miles de personas a Madrid, la exposición tan sólo registró con 73.117 personas, una cifra reconocida como baja por la propia institución, como consecuencia de la tarifa de acceso, fijada en $10 €$ por persona. 


\subsection{La gestión económica e institucional}

Patrimonio Nacional gestiona autónomamente su presupuesto que es aprobado anualmente por la Ley de Presupuestos Generales del Estado. En el año 2011 se devengaron 121.055.550€, lo que supone un $1,30 \%$ menos que en el ejercicio anterior; cifra que corresponde exactamente con los gastos realizados en ese mismo periodo. De ellos el $14,48 \%$ sería el equivalente a los ingresos propios por tasas de acceso al público, ventas y alquiler de propiedades (fig. 3). Una situación que, en una época marcada por los recortes presupuestarios, manifiesta la necesidad de establecer otros ingresos que garanticen la conservación de los bienes.

Figura 3

DISTRIBUCIÓN DEL PRESUPUESTO CORRESPONDIENTE A LOS INGRESOS DE PATRIMONIO NACIONAL EN EL AÑO 2011 (\%)

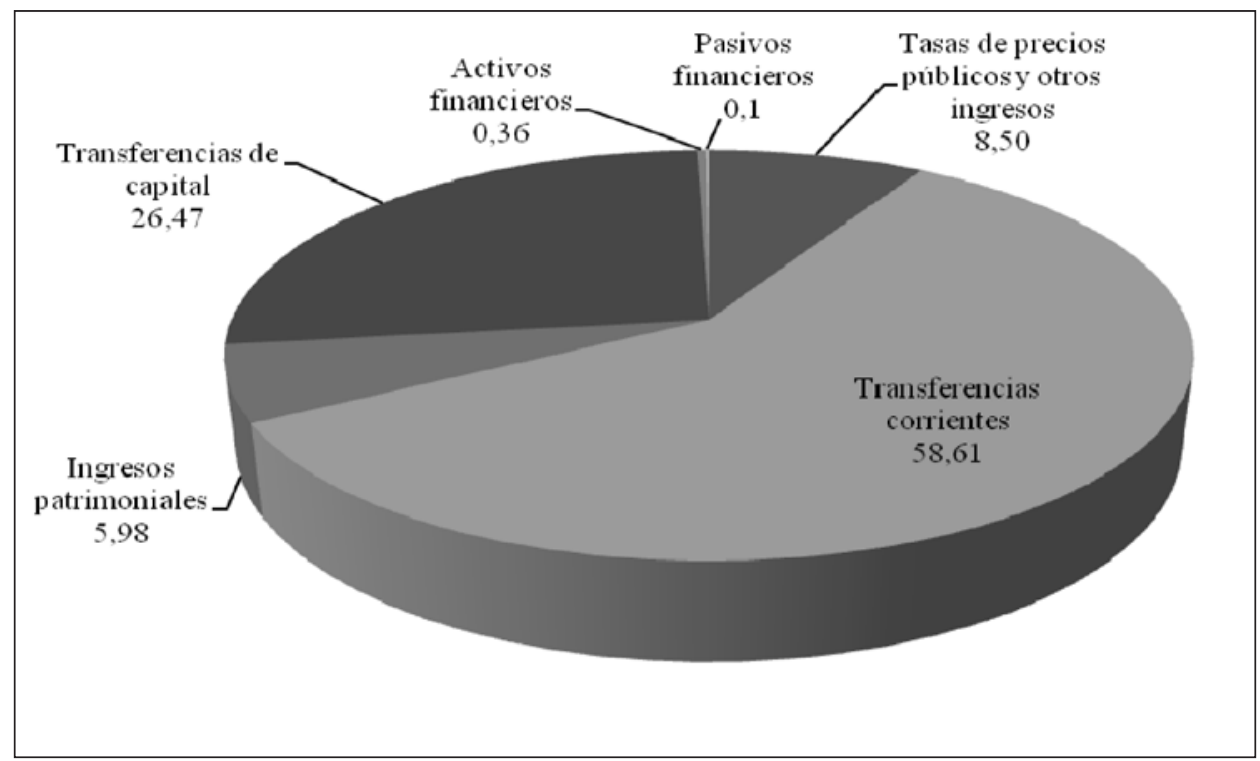

Fuente: Elaboración propia con datos de la Memoria anual del Patrimonio Nacional del 2011.

Tradición, prestigio, atractivo y saber hacer son cualidades que avalan a esta institución como una de las entidades con mayor calidad en este sector, situación que le permitiría desarrollar su potencial convirtiendo algunos de los espacios que gestiona en equipamientos culturales de referencia. Este hecho, además de posicionar a los palacios españoles en un panorama internacional, favorecería su conversión en elementos esenciales en la gestión de la institución y para el desarrollo de las localidades en las que se encuentran. De esta manera, sin suponer grandes esfuerzos económicos, puesto que Patrimonio Nacional ya tiene una programación anual que ofrece gratuitamente, se podría diseñar una oferta cultural de acceso público adecuada a los estándares económicos de otras instituciones nacionales e internacionales. Algo que, evidentemente, ayudaría a mitigar dos de los problemas esen- 
ciales a los que se enfrenta la institución: la pérdida de visitas, y por lo tanto de ingresos, y la fuerte estacionalidad que sufren algunos de sus bienes, especialmente los situados en los Reales Sitios. Este último aspecto se ha reflejado en los planes de gestión turística que se han llevado a cabo en Aranjuez (Plan de Dinamización Turística 1999-2001), San Lorenzo de El Escorial (Plan de Excelencia Turística 2003-2005) y La Granja de San Ildefonso (Plan de Dinamización Turística 2005-2008). En los tres casos se ha resaltado la necesidad de diseñar actividades culturales complementarias que, además de atraer nuevas visitas y consolidar un público que ya conoce el lugar, ayuden a reducir la concentración en determinados periodos del año y de la semana.

Sin duda, esta institución cuenta con numerosas bondades, que parecen estar insuficientemente aprovechadas o requeridas de un impulso para convertirse en actuaciones concretas con las que conseguir los fines anteriormente indicados. Por ello hace falta intervenir contra un gran número de inconvenientes, muchos de ellos internos, como son los personalismos en la gestión y la politización de la institución, que conlleva la falta de continuidad de los responsables principales (presidente, gerente...) y de las estrategias de gestión. Esto implica, por ejemplo, un fuerte temor a banalizar la imagen de la institución al presentarse a la sociedad en compañía de patrocinadores privados o de artistas vivos, ya que se considera que se podrían beneficiar directamente de la imagen, no solo de Patrimonio Nacional, sino de una institución como es la monarquía.

\section{LA GESTIÓN DE LA OFERTA TURÍSTICO-CULTURAL EN LOS HITOS PATRIMONIALES: UN ESTUDIO COMPARATIVO}

Con el objetivo de mejorar la gestión cultural de Patrimonio Nacional y ayudar a diseñar una agenda cultural realista y rentable, se ha profundizado en el conocimiento de otras instituciones culturales españolas y europeas. Así, para cada uno de los elementos seleccionados, recogidos en el apartado tercero de este artículo, se han identificado y analizado: las actividades que componen su oferta cultural, la afluencia recibida, las tarifas implantadas y las políticas de comercialización y promoción. Asimismo, se han clasificado las actividades en cuatro grupos: 1. las visitas al museo o monumento, 2. las exposiciones temporales, 3 . las actividades culturales extramuseísticas y 4 . las actividades pedagógicas.

\subsection{La agenda cultural: las actividades ofrecidas y su aceptación por el público}

Aunque el objetivo de la investigación que aquí se presenta no se centra en el estudio de la visita convencional al museo, sí interesa conocerla de manera comparativa, con el fin de establecer semejanzas y diferencias en cuanto al atractivo de cada uno de los bienes, así como la gestión que se contempla para cada uno de ellos. En este sentido Patrimonio Nacional, en su conjunto, recibe una afluencia semejante a la de la Alhambra o a la del museo de El Prado. Diferente es si comparamos cada uno de los bienes por separado. En ese caso, el Palacio Real de Madrid se encontraría ocupando el cuarto lugar respecto al número de visitas a monumentos y museos dentro de la ciudad de Madrid (fig. 4). 


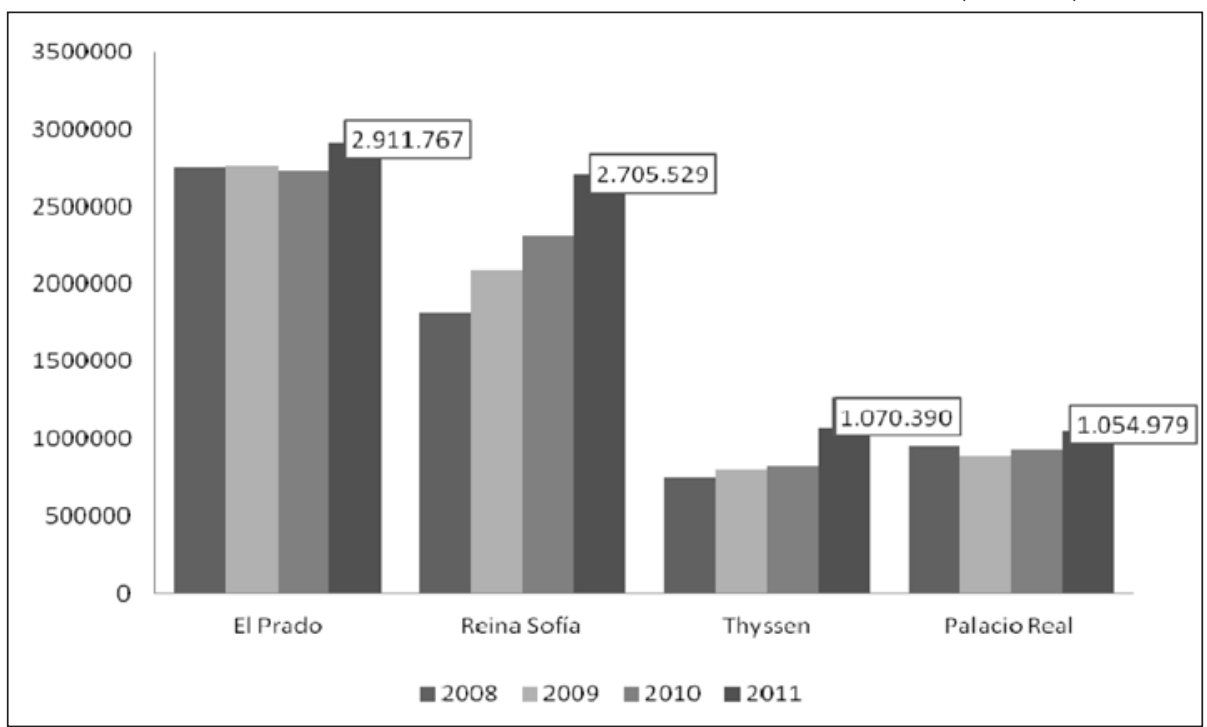

Fuente: Elaboración propia con datos de las Memorias anuales del Museo del Prado, el Museo Centro de Arte Reina Sofía, el Museo Thyssen y Patrimonio Nacional (2008-2011).

Otro hecho destacable es que, pese a la crisis económica, en los últimos cuatro años, los cuatro museos han mostrado una tendencia creciente en el número de visitas. Esto indica que existe un gran interés en el patrimonio y la cultura por parte del público, pero también que las instituciones actúan para favorecer esta recepción. Todas ellas recogen en sus misiones la importancia que tiene la visita pública, y establecen calendarios de actividades al tiempo que han intensificado las labores de difusión de la información, llegando incluso, en el caso del Museo Thyssen, a diseñar proyectos de promoción turística orientados a los profesionales del turismo.

Sin duda, parte de este crecimiento, valorado por las instituciones y los medios de comunicación como un éxito, se debe a la oferta cultural, compuesta por actividades consideradas extraordinarias. En este sentido hay que destacar que en España ésta es todavía muy limitada, siendo aún muy pocos, aunque con una tendencia creciente, los hitos patrimoniales que diseñan anualmente una agenda cultural. Centrándonos en aquellas instituciones que sí disponen de ella (Prado, Thyssen Bornemisza, Reina Sofía y Alhambra) es interesante observar la amplitud y variedad de su oferta, en la que destacan, por ser frecuentes, las exposiciones temporales. No obstante son minoritarias las instituciones españolas que diseñan, con cierta periodicidad, actividades culturales denominadas «extramuseísticas», tales como conciertos, espectáculos, representaciones teatrales, ciclos de conferencias, jornadas científicas, festivales... o que alquilan sus espacios para la celebración de eventos. Con ello se produce una mercantilización de los museos en un proceso propio de una sociedad de consumo, en el que las instituciones se ponen al servicio de la sociedad y la cultura se capitaliza, al punto de generar franquicias, como sucede con el Guggenheim (Ramos, 2007). 
De todas las acciones presentadas las que reciben un mayor número de visitas, motivadas por su carácter efímero, son las exposiciones temporales (Ramos, 2001), cuya organización es la más habitual, tanto en los museos como en los monumentos, al mostrarse como una prolongación natural del bien cultural. Éstas permiten desarrollar una de las finalidades básicas de los museos que, junto a la conservación y la investigación, consiste difundir sus fondos el arte y la cultura (Albi, 2003), al tiempo que permiten dinamizar el museo y fidelizar un público (Prats, 2000). Pese a ello, en los últimos años, los datos constatan que la afluencia recibida depende mucho de la calidad de las obras exhibidas, del renombre del artista, de la institución que la organiza, así como de la difusión realizada de las exposiciones, existiendo grandes diferencias entre museos e incluso entre las propuestas por una misma institución.

Más modesta es la propuesta de las actividades extramuseísticas, de mayor variedad en los monumentos que en los museos, al disponer para su realización de más espacios y, generalmente, de mayores dimensiones. En la esencia de muchos de estos monumentos (palacio y casas de recreo en su mayoría) estaba la celebración de espectáculos, solemnidades militares y religiosas marcadas por un importante boato, que en los últimos años han sido recuperadas y readaptadas a las características de la demanda actual. Esto sucede, por ejemplo, en la Alhambra, donde además, se celebran conciertos de música contemporánea, resaltando la esencia cultural del monumento. Igualmente, los conciertos, fuera del horario de visitas habitual, se han convertido en una actividad muy frecuente en muchos de los museos, especialmente de aquellos que no cuentan con una afluencia masiva, como sucede en algunos de los denominados Museos Estatales que ofrecen gratuitamente conciertos y recitales y, en ocasiones puntuales, también celebran conferencias y jornadas, generalmente vinculadas a los elementos que exponen. Con estas actividades los museos públicos refuerzan su función social como elementos educativos y de disfrute de la ciudadanía.

Uno de los resultados más evidentes del estudio comparativo es la diferencia clara que existe entre el comportamiento de las instituciones españolas y las extranjeras. Así, la oferta de las residencias reales europeas seleccionadas es notablemente más numerosa, diversa e innovadora que la ofrecida por los principales museos y monumentos españoles. Dentro de las residencias extranjeras destaca sobremanera Versalles, por el número de actividades que propone y por la tradición en su organización. Debido a su magnitud, a finales del año 2003, el Consejo de Administración del Etablissement Public du Musée et du Domaine National de Versailles-Chateau Versailles, decidió crear Château de Versailles Spectacles ${ }^{11}$. Una filial que nació con el encargo de perpetuar los espectáculos que durante la década anterior habían recibido más de un millón de visitantes y que, además, debía diseñar y realizar nuevos eventos culturales, de estilo clásico y contemporáneo, fieles a la historia del lugar. Un reto que ha alcanzado, al pasar de 669.738 asistentes en 2004 a 1.214.924 en 2010.

En definitiva, Versalles fue pionero en la creación de una estructura que se encargara de gestionar de forma ágil y flexible los eventos, optimizando la gestión y los costes para una mejor rentabilidad. Así, desde 2004 la institución Château Versailles se ocupa de la gestión de la visita pública, en todas sus variantes, mientras que Château Versailles Spectacles gestiona las actividades culturales, siendo responsable de su preparación, producción, ejecución,

11 Aprobado por Orden del Ministerio de Economía Finanzas e Industria francés, de 23 de diciembre de 2003, para su lanzamiento real en 2004. 
promoción y comercialización (Établissement Public du Musée et du Domaine National de Versailles, 2004).

Dentro de esta lógica de propuestas para el acercamiento de los museos al público general, destacan las actividades pedagógicas orientadas al infantil, consideradas de gran importancia, al ser clave en la enseñanza de «el arte de saber ver» ${ }^{12}$ o alfabetización de la sociedad (Jiménez, 2008) a través de la valoración del patrimonio, generando hábitos y sensibilidades que van a ser clave en las futuras generaciones de consumidores de patrimonio. Sin duda, los gestores de los principales museos y monumentos españoles son conscientes de ello y, en su mayor parte, cuentan con departamentos de Didáctica o de Educación y Acción Cultural. En ellos dedican especial atención al diseño, seguimiento, publicidad y realización de estas actividades que cuentan con diferentes programas diferenciados por edades, según se realicen de manera individual o grupal, en programas familiares o con los colegios, y también en función de épocas del año, al ser cada vez más frecuente la oferta de programas pedagógicos durante el verano.

Al comparar la oferta cultural extramuseística y la pedagógica de los museos y monumentos españoles con la ofrecida por las Residencias Reales Europeas se ve con claridad que en el segundo de los casos es más numerosa y, además, se observa que en los últimos dos años en España se ha producido una reducción de las programadas habitualmente, mientras que por el contrario, en el extranjero ha aumentado el número de actividades de este tipo. Concretamente, el Palacio de Schönbrunn ha incrementado de forma importante su oferta, con actuaciones teatrales e infantiles. Asimismo, es llamativo que en todos los casos las actividades pedagógicas cuentan con una tarifa, algo criticado por las AMPAS, quienes denuncian reiteradamente que los precios, aunque simbólicos, suponen una barrera para muchas familias, generando desigualdades sociales.

\subsection{Política tarifaria y promocional de los museos y monumentos}

Actualmente, los principales museos y monumentos, independientemente de su titularidad, tienen establecida una tarifa y cobran por disfrutar de sus colecciones e instalaciones, limitándose la gratuidad a personas con características específicas y días concretos. $\mathrm{Al}$ mismo tiempo, existe una tendencia cada vez mayor al aumento del precio de las entradas, determinado de manera muy desigual entre unos y otros. En España cada actividad tiene adjudicada una única tarifa, mientras que en la oferta extranjera cada una, dependiendo de su programación y duración, tiene establecidos varios precios. Estos varían según se trate de una tarifa normal, reducida, para grupos, familias numerosas, etc, al tiempo que reconocen unas condiciones de gratuidad, generando una variedad de opciones que dan cobijo a todos los presupuestos. Asimismo, los diferentes grados van a segregar las actividades, diferenciando un nivel más erudito o elitista, de mayor coste por la programación, los artistas y las dimensiones del espacio en el que se realiza, y otra más masificada en la que prima un acceso más libre y se ofertan más plazas (tabla 2). Ambos estilos conviven en la oferta de Versalles, Hampton Court o Shönnbrun.

12 Idea defendida por el pedagogo D. Manuel Bartolomé Cossío, perteneciente a la Institución Libre de Enseñanza. 
Tabla 2

TARIFAS DE LAS ACTIVIDADES OFRECIDAS POR LAS INSTITUCIONES CULTURALES SELECCIONADAS (€). AÑO 2011

\begin{tabular}{|c|c|c|c|c|c|c|c|c|}
\hline & Prado & Thyssen & $\begin{array}{l}\text { Reina } \\
\text { Sofía }\end{array}$ & Alhambra & Versalles & Chambord & $\begin{array}{c}\text { Hampton } \\
\text { Court }\end{array}$ & Schönnbrun \\
\hline $\begin{array}{l}\text { Exposiciones } \\
\text { temporales }\end{array}$ & $\begin{array}{c}8-10 \\
4-5\end{array}$ & $5,5-8$ & 3 & Gratuita & $\begin{array}{c}\text { Con la } \\
\text { entrada ó } \\
18-25\end{array}$ & 9,5 & 4,5 & $\begin{array}{c}\text { Con la } \\
\text { entrada ó } \\
9,5-14,50\end{array}$ \\
\hline Música clásica & Gratuita & No hay & No hay & 10 & $\begin{array}{c}13 \\
\text { (media) }\end{array}$ & $6-12$ & $\begin{array}{c}100 \\
\text { (media) }\end{array}$ & $30-90$ \\
\hline $\begin{array}{l}\text { Ciclo música o } \\
\text { teatro }\end{array}$ & No hay & No hay & Gratuita & No hay & 100 & 14 & 17 & Gratuita \\
\hline $\begin{array}{l}\text { Conciertos } \\
\text { didácticos }\end{array}$ & No hay & No hay & No hay & 10 & 14,5 & No hay & No hay & $4-7$ \\
\hline Ópera & No hay & No hay & No hay & No hay & 50 & 60 & No hay & $30-90$ \\
\hline $\begin{array}{l}\text { Conciertos } \\
\text { extraordinarios }\end{array}$ & 5 & No hay & No hay & 40 & 20 & No hay & $\begin{array}{c}100 \\
\text { (media) }\end{array}$ & No hay \\
\hline Espectáculos & No hay & No hay & No hay & No hay & $20-150$ & $10-12$ & $50-100$ & No hay \\
\hline Conferencias & 80 & Gratuita & Gratuita & Gratuita & Gratuita & Gratuita & 3 & No hay \\
\hline $\begin{array}{l}\text { Programas } \\
\text { educativos }\end{array}$ & 3 & 6 & Gratuita & 3 & 15 & 4 & $6-13-100$ & $4,50-6$ \\
\hline
\end{tabular}

Fuente: Elaboración propia con los datos de las memorias anuales y de las webs de los diferentes museos y monumentos.

Con ello se recaudan cifras, en ocasiones simbólicas, para los presupuestos que manejan las instituciones, la mayor parte de las cuales cuentan con dos tipos de ingresos: subvenciones del Estado e ingresos propios. Estos últimos corresponden a la venta de entradas y productos, al patrocinio y la cesión o gestión de espacios. Patrimonio Nacional es, tras el museo Reina Sofía, la institución que depende en un porcentaje más alto (casi el 85\%) de las subvenciones (tabla 3). Precisamente, esta dependencia de los Presupuestos Generales del Estado le ha permitido, durante décadas, realizar actividades culturales gratuitas, a algunas de las cuales solo se tiene acceso mediante invitación institucional, lo que le da un carácter elitista e implica la limitación del acceso al público interesado. 
Tabla 3

PRESUPUESTOS DE LAS INSTITUCIONES CULTURALES Y PATRIMONIALES ESPAÑOLAS Y EUROPEAS (€). AÑO 2010

\begin{tabular}{|l|c|c|c|c|c|c|}
\hline & \multicolumn{2}{|c|}{ Subvención } & \multicolumn{2}{c|}{ Ingresos propios } & \multicolumn{2}{c|}{ Total presupuesto } \\
\hline & $€$ & $\%$ & $€$ & $\%$ & $€$ & $\%$ \\
\hline Patrimonio Nacional & 104.098 .105 & 84,87 & 18.557 .845 & 15,13 & 122.655 .950 & 100,00 \\
\hline Museo del Prado & 24.156 .872 & 56,42 & 18.657 .714 & 43,58 & 42.814 .586 & 100,00 \\
\hline Museo Thyssen & 2.640 .000 & 17,18 & 12.723 .000 & 82,82 & 15.363 .000 & 100,00 \\
\hline Museo Reina Sofía & 45.838 .775 & 91,9 & 4.038 .340 & 8,1 & 49.877 .115 & 100,00 \\
\hline Alhambra & - & - & - & - & 22.436 .178 & 100,00 \\
\hline Versalles & 7.836 .000 & 13,23 & 51.385 .000 & 86,77 & 59.221 .000 & 100,00 \\
\hline Chambord $^{(1)}$ & 3.279 .980 & 22,00 & 11.629 .020 & 78,00 & 14.909 .000 & 100,00 \\
\hline
\end{tabular}

Fuente: Elaboración propia a partir de los datos de las memorias anuales.

(1) Presupuesto para el año 2008. Chambord tiene una gran extensión forestal que genera el $67 \%$ de los beneficios directos, gracias a la concesión de permisos de caza y a la venta de madera.

Con el fin de obtener una rentabilidad económica, que redujera el porcentaje ingresado mediante subvención, y favorecer el acceso democrático a todas actividades, se realizó una simulación en el citado «Estudio económico sobre las actividades culturales de Patrimonio Nacional». Ésta se basada en las cifras de afluencia de los museos de Patrimonio Nacional en el año 2011 y en unas tarifas medias predefinidas, similares a las establecidas en las instituciones analizadas (tabla 2). Con ello se llegó a la conclusión orientativa de que Patrimonio Nacional dejaba de percibir anualmente entre 1.150 .000 y 1.500 .000 euros, cantidades que en este contexto se presentan como anecdóticas, pero que ponen de manifiesto la posibilidad de diversificar sus fuentes de ingresos y la imposibilidad, actual, para establecer otros modelos gestión. Esto se debe a la carencia de herramientas de gestión modernas y ágiles, que permitan desempeñar tareas de organización, contratación, venta de entradas, etc, algo de lo que sí disponen otros hitos patrimoniales y culturales. Y es que la mayoría de las instituciones culturales españolas, salvo los Museos Estatales y Patrimonio Nacional, cuentan con el apoyo de entidades bancarias para llevar a cabo las tareas de venta de entradas del museo y de las diferentes actividades extramuseísticas que ofrecen. Así, algunas, como los museos de El Prado, Reina Sofía y Thyssen disponen de sus propios centros de atención al visitante, que gestiona la venta de entradas telefónica y on line e incluso venden sus entradas a través de El Corte Inglés, bien directamente en las tiendas y por Internet. Otros, como la Alhambra lo gestiona en colaboración con instituciones bancarias, siendo pionera en este servicio que comenzó en colaboración con el BBVA y que continúa con La Caixa, que mediante Serviticket o directamente en sus cajeros automáticos, se encarga de la reserva y venta de entradas. Un comportamiento común con las Residencias Reales Europeas, que comercializan su visita a través de empresas como FNAC, en el caso francés, o directamente en sus propias tiendas online como sucede en Schönbrunn o Hapton Court.

Por último, destacar la importancia que en la promoción de las visitas a los museos, de las exposiciones temporales, de las actividades culturales extramuseísticas y de las actividades pedagógicas tienen las nuevas formas de promocionar la cultura. Entre ellas destaca el uso de 
las redes sociales, una iniciativa, a la que se han sumado la práctica totalidad de las instituciones extranjeras y gran parte de las españolas, sin excepción de su índole o de los públicos a los que son destinadas. Así, Flickr, Facebook, Twiter, Tuenti, Menéame, Youtube o Google Art Project se han transformado en la forma más dinámica y directa de establecer comunicación entre los profesionales de los museos y un público afín e interesado en la oferta cultural, lo que además permiten su fidelización (Del Río, 2011).

Un tejido o red del que también carece Patrimonio Nacional, impidiendo que llegue a gran parte del público objetivo y que fidelice a sus visitantes. Esta ausencia dificulta enormemente la puesta en valor de gran parte de su rico patrimonio, lo que además de repercutir directamente en los destinos de visita cultural en los que se encuentra, perjudica su comprensión y conocimiento. Esto se debe a que las Webs 2.0 permiten el desarrollo de un modelo de difusión más democrático y, sobre todo más participativo, hasta el punto de convertirse en la vía de la canalización de la inteligencia social o colectiva (O'Reilly, 2009). Algo que supera el tradicional mensaje institucional y descriptivo tan frecuente en las webs de los museos, lo que Walsh denomina la «voz incuestionable».

\section{CONCLUSIONES}

La situación actual, marcada por la competitividad y una demanda cada vez más exigente, ha llevado a que las instituciones patrimoniales y culturales realicen importantes cambios o, cuanto menos, una significativa reflexión acerca de su misión y de los modelos de gestión que llevan a cabo. Estas modificaciones hacen que la gestión se racionalice y que la organización institucional sea cada vez más compleja, en busca de un equilibrio que garantice: el estado de conservación de bienes que están a su cargo, la calidad de la visita adaptada a las necesidades de una demanda creciente y especializada y, por último, el desembolso de los elevados costes que implica la conservación y la consolidación de una oferta cultural atractiva y variada. Con todo ello se han diseñado una gran variedad de formas y estrategias de gestión, que presentan un panorama muy desigual y genera grandes diferencias entre los destinos con atractivo turístico, en muchos de los cuales las intervenciones de sus instituciones resultan determinantes.

En el caso concreto de Patrimonio Nacional, su vinculación con la Corona supone un importante hándicap que lejos de ser aprovechado, como un recurso atractivo para los visitantes, es considerado un factor limitante en la organización y la gestión de estos lugares. Esto se debe esencialmente, a la necesidad de tener acondicionados y disponibles algunos espacios para los actos oficiales. Aun así, son minoritarios los bienes que presentan un uso institucional (Palacio Real de Madrid y Palacio de El Pardo), lo que se ponen de manifiesto: 1. las numerosas dificultades (funcionales, administrativas y económicas) a las que se enfrenta la institución y que imposibilitan el diseño de actividades culturales innovadoras que aprovechen esa oportunidad y 2. la consideración que se tiene de la función de la alta representación del estado y la imagen que ésta implica, la cual impide la incorporación de patrocinadores o la participación de artistas vivos. Una idea que no está regulada por ninguna normativa, sino que obedece a percepciones y decisiones internas, e incluso personales, basadas en el temor a banalizar la imagen de la institución y a la posibilidad de generar tratos de favor. 
Patrimonio Nacional como stakeholder de numerosos e importantes destinos turísticos, como Madrid, San Lorenzo de El Escorial, La Granja de San Ildefonso, Aranjuez o Palma de Mallorca, entre otros, debería consensuar sus estrategias principales con los agentes que gestionan los destinos en los que se encuentran sus bienes, así como con los responsables autonómicos que se encargan de establecer las actuaciones turísticas a nivel regional. Además, como agente público, debería también aprovechar el gran potencial del que dispone para crear nuevas actividades culturales, que favorezcan la mayor difusión de sus recursos y que estos puedan ser disfrutados por una mayor cantidad de visitantes. Esto implica el diseño de una agenda cultural de calidad, así como la necesitad de establecer tarifas para cada una de las actividades, que permitan nuevos ingresos para asegurar la conservación de los bienes. Con ello, lejos de reducir el acceso a las mismas, se socializaría su acogida, ya que precios segmentados en función de los visitantes, así como adaptados o inferiores a los del mercado, van a dar oportunidad a toda la población y permiten su fidelización. De esta manera, el acceso al patrimonio ayudará en el proceso de aprendizaje y en su valoración y respeto por el mismo.

Con este tipo de medidas, se contribuirá de forma directa al desarrollo económico local de cada uno de los destinos, y se reforzará su misión como institución pública de carácter cultural, al tiempo que se podrán generar nuevos públicos. Pero para poder realizar esta reestructuración es necesario llevar a cabo, en primer lugar, un replanteamiento interno que conlleve asumir la necesidad de un cambio; en segundo lugar reconocer las limitaciones de un modelo de gestión basado exclusivamente en las subvenciones y, en tercer y último lugar, implantar un órgano de gestión moderno -bien una Fundación o una Asociación- de carácter público y gestión privada que facilite el desarrollo de nuevas actividades y el establecimiento de nuevas alianzas. La figura elegida ha de permitir, además, desarrollar las tareas de comercialización que requieren las actividades culturales, de forma eficaz y adaptándose a las necesidades de la sociedad actual.

\section{BIBLIOGRAFÍA}

ALBI IBAÑEZ, E. (2003): Economía de las artes y política cultural. Madrid. Instituto de Estudios Fiscales.

ALONSO IBAÑEZ, M. R. (1991): El patrimonio histórico: destino público y valor cultural. Madrid. Civitas ediciones.

ÁVILA BERCIAL, R y BARRADO TIMÓN, D. (2005): «Nuevas tendencias en el desarrollo de destinos turísticos: marcos conceptuales y operativos para su planificación y gestión». Cuadernos de Turismo, $\mathrm{n}^{\circ}$ 15, 27-43.

BALLÉ, C. (1996): «La modernisation des musées, les paradoxes d'une évolution» en Musées: gérer autrement (Tobelem, J.M., dir). Paris, La documentation française.

BALLÉ, C. (2003): «Musées, changement et organisation». Culture \& Musées, $\mathrm{n}^{\circ} 2$, 17-33.

BARRADO TIMÓN, D. (2004): «El concepto de destino turístico. Una aproximación geográfico-territorial». Instituto de Estudios Turísticos, n ${ }^{\circ} 160,45-68$.

CASTELLS OLIVÁN, M. (1997): La era de la información: economía, sociedad y cultura. Vol. 1: La sociedad red. Madrid. Ed. Alianza.

CHATELAIN, S. (1998): «Du budget administratif au budget outil de gestion. Le cas des musées français». Finance Contrôle Stratégie, vol.1, n 3, 5- 33. 
CHINCHILLA GÓMEZ, M. (2007): «Una propuesta de itinerario para un recorrido por los Museos Estatales». Museos.es: Revista de la Subdirección General de Museos Estatales, $\mathrm{n}^{\circ} 3,148-159$.

COHEN, E. (2005): «Principales tendencias en turismo contemporáneo». Revista Política y Sociedad, vol. 42, $\mathrm{n}^{\circ} 1,11-24$.

DE LA CALLE VAQUERO, M. (2002): La ciudad histórica como destino turístico. Barcelona. Ed. Ariel.

DE LA CALLE VAQUERO, M. y GARCÍA HERNÁNDEZ, M. (1998): «Ciudades históricas: patrimonio cultural y recurso turístico». Ería, no 47, 249-266.

DEL RÍO CASTRO, J.N. (2011): «Discursos paralelos: la di-fusión en museos online de Arte contemporáneo» en La Web 2.0 y 3.0 en su relación con el EEES (Gonzálvez Valles, J.E., coord.). Madrid, Visión Libros, 99-118.

DÍEZ MORENO, F. (1989): «La evolución constitucional del Patrimonio Nacional». Reales Sitios, $\mathrm{n}^{\circ}$ 100, Número extraordinario XXV Aniversario, 15-30

ÉTABLISSEMENT PUBLIC DU MUSEE ET DU DOMAINE NATIONAL DE VERSAILLES. (2004): Rapport d'activité 2004 de l'Établissement Public du Musée et du Domaine National de Versailles (documento interno).

FLEURY, L. (2006): Sociologie de la culture et des pratiques culturelles. Paris. Armand Colin. FREEMAN, R. E. (1984): Strategic management. A Stakeholder Approach. London. Pitman. GARCÍA HERNÁNDEZ, M. (2004): «Ávila: Planificación y gestión turística local en una ciudad patrimonio de la humanidad» en Casos de turismo cultural (Fond, J., ed.). Barcelona. Ariel. 413-441.

GARCIA HERNANDEZ, M. y DE LA CALLE VAQUERO, M. (2012): «Los hitos patrimoniales de dimensión turística. Castilla y León y la Real Colegiata de San Isidoro». Polígonos. Revista de Geografía, no 23, 113-145

GARCIA HERNANDEZ, M y MÍNGUEZ GARCÍA, M.C (2005): «Funcionalidad turística de los reales sitios españoles: problemas y perspectivas». Ería, vol. 66, 71-84.

GOMBOULT, A. (2003): «La nouvelle identité organisationnelle des musées. Le cas du Louvre». Lavoisier |Revue française de gestion, $\mathrm{n}^{\circ}$ 142, 189-203.

KAVANAGH (1994): Museum Provision and Professionalism. Londres y Nueva York. Ed. Routledge.

LORD, B y LORD, G. D. (1998): Manual de Gestión de Museos. Barcelona. Ed. Ariel.

MERINERO RODRIGUEZ, R. y PULIDO FERNÁNDEZ, J.I. (2009): «Desarrollo turístico y dinámica relacional. Metodología de análisis para la gestión activa de destinos turísticos». Cuadernos de Turismo, $\mathrm{n}^{\circ} 23,173-193$.

MERINERO RODRIGUEZ, R. y ZAMORA ACOSTA, E. (2009): «La colaboración entre los actores turísticos en ciudades patrimoniales. Reflexiones para el análisis del desarrollo turístico». Pasos. Revista de Turismo y Patrimonio Cultural, vol. 7, nº 2, 219-238.

MÍNGUEZ GARCÍA, M. C. (2007): «Planificación y gestión turística en destinos patrimoniales: el caso del Real Sitio de San Lorenzo de El Escorial». Anales de Geografía de la Universidad Complutense, $\mathrm{n}^{\mathrm{o}} 27$ (1), 83-102.

MONTERO MURADAS, I; GUTIÉRREZ TAÑO, D. y DÍAZ ARMAS, R. (2001): «La cultura como componente de la oferta de los destinos turísticos maduros». Estudios Turísti$\cos , \mathrm{n}^{\mathrm{o}} 150,41-55$. 
OMT. (2004): Gestión de la saturación turística en sitios de interés natural y cultural. Madrid. Organización Mundial de Turismo.

O'REILLY, T. (2007): «What is Web 2.0? Design Patterns and Business Models for the Next Generation of Software». Communications \& Strategies, International journal of digital economics, $\mathrm{n}^{\circ}$ 65, 17-37.

PATRIMONIO NACIONAL. Memorias Anuales, varios años (documento interno).

PRATS, C. (2000): Plan museológico y exposiciones temporales. Museo, nº 5, 43-49.

RAMOS LIZANA, M. (2001): «El fenómeno social de las exposiciones temporales». $P H$ Boletín, n 34, 146- 158.

RAMOS LIZANA, M. (2007): El turismo cultural, los museos y su planificación. Gijón: Trea.

RICHARDS, G. (1996): «Production and consumption of European cultural tourism». Annals of Tourism Research, vol. 23, Issue 2, 261-283.

RICHARDS, G. (2001a): «El desarrollo del turismo cultural en Europa». Estudios Turísticos, $\mathrm{n}^{\circ} 150,3-13$.

RICHARDS, G. (2001b): «Development of cultural tourism and cultural attractions». En Cultural attractions and European tourism (Richards, $\mathrm{G}$ ed.). Wallingford. CAB International, 3-29.

SANTANA TALAVERA, A. (2003): «Patrimonios culturales y turistas: unos leen lo que otros miran». Pasos. Revista de Turismo y Patrimonio Cultural, vol. 1, n 1, 1-12.

SELBACH, G. (2000): Les musées d'art américains: une industrie culturelle. Paris. L'Harmattan, Collection Esthétiques.

TOBELEM, J.M. (2007): «The Marketing Approach in Museums». Museums Management and Curatorship, vol. 16, n 4, 337-354.

TROITIÑO, M.A; BRANDIS, D; DEL RÍO, I, CALLE, M; GUTIÉRREZ, J; LOBO, P. y MARTÍN, F. (1998): «Toledo: problemática e implicaciones urbanas del turismo». Ería, $n^{\circ} 47,299-325$.

TROITIÑO VINUESA, M. A y TROITIÑO TORRALBA, L. (2008): «Patrimonio, turismo cultural y museos en España». Rev. Amigos de los Museo. Boletín Informativo, $\mathrm{n}^{\mathrm{o}} 26$, 16-18.

TROITIÑO VINUESA, M. A y TROITIÑO TORRALBA, L. (2009): «Turismo y Patrimonio en Castilla y León: Las Ciudades Patrimonio de la Humanidad (Ávila, Salamanca y Segovia) como destinos turísticos de referencias». Polígonos. Revista de Geografía, no 19, 145-178.

URRY, J. (1995): Consuming places. London. Routledge.

VACAS GUERRERO, T. (2000): «Los museos madrileños como oferta turístico-cultural». Cuadernos de Turismo, $\mathrm{n}^{\circ}$ 5, 105-111.

VELASCO GONZÁLEZ, M. (2009): «Gestión turística del patrimonio cultural: enfoques para un desarrollo sostenible del turismo cultural». Cuadernos de Turismo, n 23, 237-253.

VERA REBOLLO, F (coord.); LÓPEZ PALOMEQUE, F; MARCHENA GÓMEZ, M. y ANTON CLAVÉ, S. (1997): Análisis territorial del turismo, una nueva geografía del turismo. Barcelona. Ed. Ariel.

WALSH, P. (1997): «The Web and the Unassailable Voice». Archives and Museum Informatics, $\mathrm{n}^{\mathrm{o}} 11,77-85$. 